hypotension, nausea, dryness of the mouth, and rashes. The ward staff are familiar with the routine postoperative checks of blood pressure, pulse, and temperature, these being done hourly for the first six hours and four-hourly thereafter. After six hours enough time has elapsed for any abnormal response to the drug to be noticed. The most important value is the respiratory rate. This must be checked hourly and a clear indication given to the nursing staff of the minimum rate acceptable before action should be taken. The time taken to recharge the microdrop dispenser and count the respiration rate is just over a minute, but the routine of intramuscular injections is also time-consuming. Furthermore, a patient with no pain can help himself in bed more readily than one in pain, who may require constant nursing attention for minor nursing details; thus more time may be spent attending to the general well-being of the patients rather than complying with the stringent rules associated with the administration of intramuscular narcotics.

Almost undoubtedly the success of a continuous narcotic infusion rests on its management, and in wards in which the nursing staff are interested and involved the results are much better than in those where the staff are too busy or preoccupied to allow such treatment to work. Ideally a pain team should administer the postoperative analgesia: this could consist of a small group of interested and experienced nursing sisters under the direction of an anaesthetist. The team would be responsible not only for organising the narcotic infusion regimen but also for topping up epidural catheters on the wards.

I am indebted to the surgeons and anaesthetists for allowing me to develop this technique on patients under their care. I should also like to express my gratitude to the recovery ward staff and the pharmacy department for the help they have provided, and to Mrs Louise Boxwell for her secretarial help.

\section{References}

${ }^{1}$ British Medical fournal, 1978, 2, 517.

2 Anaesthesia and Intensive Care, 1976, 4, 95.

3 Wallace, P G, and Norris, W, British fournal of Anaesthesia, 1975, 47, 113. ${ }^{4}$ Cronin, M, Redfern, P A, and Urring, J E, British fournal of Anaesthesia, 1973, 45, 879.

${ }^{5}$ Stapleton, J V, Austin, K L, and Mather, L E, British Medical fournal, 1978, 2, 1499.

\title{
Glycosylated haemoglobin concentrations in newly diagnosed diabetics before and during treatment
}

\author{
D M FRASER, A F SMITH, R S GRAY, D Q BORSEY, M E SINCLAIR, B F CLARKE, \\ L J P DUNCAN
}

British Medical fournal, 1979, 1, 979-981

\section{Summary and conclusions}

Concentrations of total glycosylated haemoglobins (Hb $A_{1}$ ) were measured in $\mathbf{4 0}$ diabetics at diagnosis and at monthly intervals after treatment with chlorpropamide, insulin, or diet alone was begun. The mean $\mathbf{H b} \mathbf{A}_{1}$ concentration at presentation in 16 patients treated with chlorpropamide was significantly higher than that in 12 patients treated with insulin, and the duration of glycaemic symptoms was much longer in the chlorpropamidetreated group. In contrast, the mean plasma glucose concentration was similar in both groups. The mean concentrations of $\mathrm{Hb} A_{1}$ and plasma glucose at diagnosis in the 12 patients treated by diet alone were lower than those in the other two groups, and most of these patients were free of symptoms. Treatment quickly relieved

Diabetic Department, Royal Infirmary, Edinburgh EH3 9YW

D M FRASER, MB, MRCP, senior registrar

R S GRAY, MB, MRCP, senior registrar

D Q BORSEY, MB, MRCP, registrar

B F CLARKE, MB, FRCP, consultant physician

L J P DUNCAN, MB, FRCP, consultant physician

University Department of Clinical Chemistry, Royal Infirmary, Edinburgh

A F SMITH, MD, FRCP, senior lecturer

M E SINCLAIR, MSC, biochemist symptoms and lowered plasma glucose in all patients. The $H b A_{1}$ concentration fell significantly with treatment such that after two months there was no significant difference between the three groups, although results remained above the normal range.

These findings support the theory that the $\mathrm{Hb} \mathbf{A}_{1}$ concentration reflects the blood glucose control over the previous one to two months and suggest that the duration of hyperglycaemia may be important in determining the $\mathrm{Hb} \mathrm{A}_{1}$ concentration as well as the absolute blood glucose concentration.

\section{Introduction}

Haemoglobin $A_{1_{c}}\left(\mathrm{Hb} A_{1 c}\right)$ is produced via a post-synthetic glycosylation of haemoglobin $A,{ }^{1}$ probably by a slow and nonenzymatic process within the red blood cell throughout its 120-day life span, the concentration being highest in the oldest erythrocytes. Thus the concentration of $\mathrm{Hb} \mathrm{A}_{\mathbf{1}_{\mathrm{c}}}$ usually reflects the mean blood glucose concentration prevailing over the previous few months. ${ }^{2}$ When the blood glucose concentration improves in poorly controlled diabetics raised $\mathrm{Hb} \mathrm{A}_{1 \mathrm{c}}$ concentrations decrease towards normal values. ${ }^{3}$ Ditzel and Kjaergaard ${ }^{4}$ reported that raised concentrations of $\mathrm{Hb} \mathrm{A}_{\mathrm{ic}_{\mathrm{c}}}$ in newly diagnosed diabetics fell towards normal two to four months after the start of treatment. All their patients, however, were treated with insulin, irrespective of age or the severity of hyperglycaemia at diagnosis, and all were initially inpatients. We have investigated a group of newly diagnosed diabetics, both insulin-dependent and independent, whose disease was of varying severity, in an attempt to correlate the concentration of total glycosylated haemoglobins $\left(\mathrm{Hb} \mathrm{A}_{1}\right)$ with the duration of glycaemic symptoms 
and the plasma glucose concentration at diagnosis, and have followed the progress of these patients over four months according to the type of treatment given.

\section{Patients and methods}

We studied 40 newly diagnosed non-obese (under $115^{\circ}$ of standard weight) diabetic patients ( 20 men, 20 women). Twelve patients, none of whom was severely ketotic at diagnosis, were treated with insulin (usually by twice daily injections of short- and intermediate-acting insulins). Sixteen patients were treated with a sulphonylurea (chlorpropamide) from the time of diagnosis, and 12 with diet alone. The indication for starting chlorpropamide treatment in all cases was hyperglycaemia associated with unacceptable symptoms (thirst, polyuria, pruritus vulvae). The table shows the clinical details of the patients. The duration of glycaemic symptoms in the insulin-treated

Details of age, sex, body weight, and duration of symptoms in the three treatment groups. Results expressed as means $\pm S E$ of mean

\begin{tabular}{|c|c|c|c|c|c|}
\hline \multirow{2}{*}{ Treatment } & \multirow{2}{*}{ Age (years) } & \multicolumn{2}{|c|}{ Sex } & \multirow{2}{*}{$\begin{array}{l}\text { Body weight } \\
\text { (\% standard } \\
\text { weight) }\end{array}$} & \multirow{2}{*}{$\begin{array}{c}\begin{array}{c}\text { Duration } \\
\text { of } \\
\text { symptoms }\end{array} \\
\text { symong }\end{array}$} \\
\hline & & $M$ & $\mathrm{~F}$ & & \\
\hline $\begin{array}{l}\text { Insulin } \\
(n=12)\end{array}$ & $35 \cdot 9 \pm 10 \cdot 4$ & 6 & 6 & $94 \pm 11$ & 1-4 weeks \\
\hline $\begin{array}{c}\text { Chlorpropamide } \\
(\mathrm{n}=16)\end{array}$ & $58 \cdot 3 \pm 2 \cdot 4$ & 7 & 9 & $99 \pm 10$ & $1-18$ months \\
\hline $\begin{array}{c}\text { Diet alone } \\
(\mathrm{n}=12)\end{array}$ & $62 \cdot 6 \pm 3 \cdot 1$ & 7 & 5 & $102 \pm 11$ & 1-2 months* \\
\hline
\end{tabular}

*Nine patients were asymptomatic at diagnosis.

group was one to four weeks compared with one to 18 months in the chlorpropamide-treated group. Of the 12 patients treated by diet alone, nine were asymptomatic, the diagnosis being suspected from the results of routine urine analysis; in the remaining three patients the symptoms lasted for one to two months.

Venous blood samples (usually obtained one to two hours postprandially) were taken at diagnosis and at monthly intervals for four months for estimation of $\mathrm{Hb} \mathrm{A}_{1}$ and plasma glucose concentrations. Samples were haemolysed on the day of receipt, stored thereafter at $4^{\circ} \mathrm{C}$, and analysed within four days. No change in the $\mathrm{Hb} \mathrm{A} \mathrm{A}_{1}$ concentration occurred under these conditions of storage. The $\mathrm{Hb} \mathrm{A}_{1}$ concentration was measured by the method of Kynoch and Lehmann, slightly modified as follows: buffer was pumped through the column at a rate of $150 \mathrm{ml} /$ hour, the column was pre-equilibrated with buffer for 100 minutes, and $125-\mathrm{ml}$ fractions were collected. In our laboratory the coefficient of variation of the method, calculated from serial analysis of patients' specimens, was $3 \cdot 2 \%$. The normal range for $\mathrm{Hb} \mathrm{A}_{1}$ concentration in our laboratory is $6 \cdot 0-7 \cdot 6 \%$. Plasma glucose concentration was measured by a glucose oxidase method using the Technicon AutoAnalyzer.

All results were expressed as means $\pm S E$ of mean, and statistical significance was assessed by Student's $t$ test.

\section{Results}

The figure shows the mean concentrations of plasma glucose and $\mathrm{Hb} \mathrm{A}_{1}$ at diagnosis and at each month of follow-up. The mean plasma glucose concentration at diagnosis was similar in both the insulin- and chlorpropamide-treated groups and in both cases was significantly higher $(P<0.01)$ than the concentration in patients treated by diet alone. The mean $\mathrm{Hb} \mathrm{A}_{1}$ concentration at diagnosis in the chlorpropamide-treated group $(16.9 \pm 0.7 \%)$ was significantly higher $(P<0.001)$ than that in both the insulin-treated group $(13.7 \pm 0.8 \%)$ and the patients receiving diet alone $(11 \cdot 8 \pm 0 \cdot 6 \%)$. Although the mean concentration in the insulin-treated group was higher than that in the patients treated by diet alone, this difference was not significant. In all patients glycaemic symptoms were resolved and the mean plasma glucose concentration had fallen by the end of the first month of treatment. Thereafter this concentration did not differ significantly between the three groups. Although the mean $\mathrm{Hb} \mathrm{A}_{1}$ concentration also fell in all three groups, the difference between the chlorpropamidetreated patients and the other two groups was still significant $(\mathbb{P}<0.01)$ at one month, but by two months and thereafter there was no significant difference. Throughout the study the mean $\mathrm{Hb} \mathrm{A}_{1}$ concentrations in all patients remained above the normal range for non-diabetic subjects. The $\mathrm{Hb} \mathrm{A}_{1}$ concentration at four months was within the normal range in only one insulin-treated patient and two chlorpropamide-treated patients compared with six of the patients treated by diet alone. The concentrations in these patients at diagnosis, however, were not significantly different from those in other patients in the
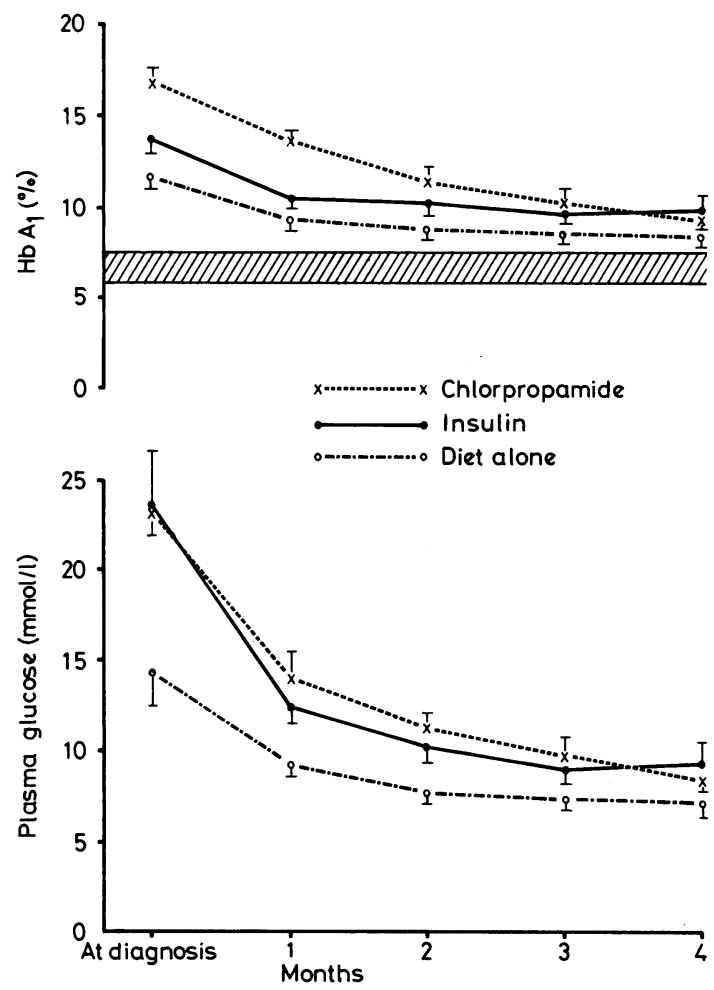

Total concentrations of glycosylated haemoglobins ( $\left.\mathrm{Hb} \mathrm{A}_{1}\right)$ and plasma glucose in 40 diabetics treated with chlorpropamide, insulin, or diet alone at diagnosis and at monthly intervals during treatment. Shaded area shows normal range for $\mathrm{Hb} \mathrm{A}_{1}$ concentrations.

Conversion: SI to traditional units-Plasma glucose: $1 \mathrm{mmol} / 1 \approx 18 \mathrm{mg} / 100 \mathrm{ml}$.

same groups. The final mean $\mathrm{Hb} \mathrm{A}_{1}$ concentrations, after four months, were $9.8 \pm 0.3 \%$ in the insulin-treated patients, $9.3 \pm 0.4 \%$ in the chlorpropamide-treated patients, and $8.6 \pm 0.3 \%$ in those treated by diet alone.

\section{Discussion}

We have shown that the $\mathrm{Hb} \mathrm{A}_{1}$ concentration is raised in all diabetics at diagnosis. The highest concentrations are found in maturity-onset diabetics with glycaemic symptoms of long duration and high plasma glucose concentrations at diagnosis. These patients were treated with chlorpropamide from the time of diagnosis since we thought that they were unlikely to respond satisfactorily to treatment with diet alone (predicted diet failures ${ }^{6}$ ). In contrast, the $\mathrm{Hb} \mathrm{A}_{1}$ concentrations in the patients treated by diet alone, most of whom were asymptomatic at diagnosis, were significantly lower, indicating a milder degree and probably shorter duration of glucose intolerance. The younger, insulin-dependent diabetics, with acute onset of symptoms, had lower $\mathrm{Hb} \mathrm{A}_{1}$ concentrations when compared with those treated with chlorpropamide, despite having similar plasma glucose concentrations. This suggests that the duration of hyperglycaemia may be important in determining the $\mathrm{Hb} \mathrm{A}_{\mathrm{H}}$ concentration in addition to the absolute concentration of blood glucose, and conflicts with the view that $\mathrm{Hb} \mathrm{A}_{1}$ concentrations may rise over a relatively short period, such as after an episode of ketoacidosis.? 
In all three groups treatment relieved symptoms quickly and lowered plasma glucose concentrations. In addition the $\mathrm{Hb} \mathrm{\textrm {A } _ { 1 }}$ concentrations fell in all patients, but even at four months after diagnosis the values remained above the normal range for nondiabetics. Previous studies ${ }^{8} 9$ have suggested that the $\mathrm{Hb} \mathrm{A_{1 }}$ concentration probably reflects the mean blood glucose concentration over the previous one to two months, and the results of our study confirm this view. The rate of fall of the $\mathrm{Hb} \mathrm{A}_{1}$ concentration with treatment was uniform in all three groups, which is compatible with the fact that glycosylation of haemoglobin is an irreversible process. ${ }^{10}$ Consequently the $\mathrm{Hb} \mathrm{A}_{1}$ concentration will fall only as new red cells that are glycosylated at a lower prevailing blood glucose concentration are produced, so diluting the higher $\mathrm{Hb} \mathrm{A}_{1}$ concentrations in older red cells.

Measuring the $\mathrm{Hb} \mathrm{A}_{1}$ concentration at diagnosis in maturityonset diabetics may be a useful additional means of predicting those patients likely to respond to diet alone and those likely to require treatment with an oral hypoglycaemic agent. It also reliably assesses diabetic control when new methods of treating diabetics are to be compared, replacing the traditional but less satisfactory estimations of urinary and plasma glucose concentrations.

We are grateful to Pfizer Ltd for support in setting up the assay for glycosylated haemoglobins.

\author{
References \\ ${ }^{1}$ Bunn, H F, et al, Biochemistry and Biophysics Research Communications, \\ $1975,67,103$. \\ ${ }^{2}$ Fluckiger, R, et al, Diabetologia, 1977, 13, 393. \\ ${ }^{3}$ Koenig, R J, et al, New England fournal of Medicine, 1976, 295, 417. \\ 4 Ditzel, J, and Kjaergaard, J-J, British Medical fournal, 1978, 1, 741. \\ ${ }^{5}$ Kynoch, P A M, and Lehmann, H, Lancet, 1977, 2, 16. \\ ${ }^{6}$ Clarke, B F, and Campbell, I W, Lancet, 1975, 1, 246. \\ 7 Paulsen, E P, and Koury, M, Diabetes, 1976, 25, suppl No 2, p 890. \\ ${ }^{8}$ Gonen, B, et al, Lancet, 1977, 2, 734. \\ ${ }^{9}$ Gabbay, K H, et al, fournal of Clinical Endocrinology and Metabolism, 1977, \\ 44, 859. \\ ${ }^{10}$ Peterson, C M, and Jones, R L, Annals of Internal Medicine, 1977, 87, 489.
}

(Accepted 16 February 1979)

\title{
Precision in estimating gestational age and its influence on sensitivity of alphafetoprotein screening*
}

\author{
C J ROBERTS, B M HIBBARD, D R EVANS, K T EVANS, K M LAURENCE, \\ MARGUERITA HOOLE, E ROBERTS, W P ENNIS
}

British Medical fournal, 1979, 1, 981-983

\section{Summary and conclusions}

The interpretation of maternal serum $\alpha$-fetoprotein (AFP) concentrations in relation to fetal neural tube defects depends on accurate assessment of the gestational age. In a quadruple-blind study three antenatal methods of assessment-namely, menstrual dates, clinical examination, and ultrasound scanning-were correlated with postnatal assessment using the Dubowitz scoring system. The best agreement to \pm 1 week was obtained using menstrual dates and ultrasound in combination, such agreement being found in $91(77 \%)$ of the 118 women studied.

Since serum AFP concentrations vary with gestational age, precise gestational dating is necessary. In many cases, particularly in women who are unsure of their dates or have irregular menstrual cycles, ultrasound examination is needed to supplement clinical findings.

*This study was conducted as part of the South Wales Anencephaly and Spina Bifida Study.

Welsh National School of Medicine, Cardiff CF4 4XN C J ROBERTS, MD, PHD, professor of community medicine B M HIBBARD, MD, FRCOG, professor of obstetrics and gynaecology D R EVANS, MB, MRCP, lecturer in child health

K T EVANS, FRCP, FRCR, professor of diagnostic radiology

K M LAURENCE, DSC, FRCPATH, professor of paediatric research

MARGUERITA HOOLE, SRN, SCM, research midwife, South Wales

Anencephaly and Spina Bifida Survey Group

E ROBERTS, DRC, instructor in diagnostic techniques

W P ENNIS, analyst programmer, department of community medicine

\section{Introduction}

The report of the UK Collaborative Study on using serum $\alpha$-fetoprotein (AF) estimations to detect neural tube malformations ${ }^{1}$ pointed out that the screening test for maternal serum AFP concentrations may be affected by the accuracy with which gestational age is measured. Because only one centre in the study reported more than $2 \%$ of pregnancies with doubtful gestational ages they were unable to examine this problem. Yet in the 1970 survey of British births gestational age was uncertain in $17 \%$ of cases, ${ }^{2}$ and Beazley and Underhill ${ }^{3}$ found uncertain dates in $22 \%$ of patients. The early experience of our group suggested a similar figure. Unlike in most biochemical investigations the transition of AFP concentrations from normal to abnormal values is related to time, and the accuracy of estimations of gestational age is emerging as a key issue in the interpretation of AFP concentrations.

There are three principal methods of assessing gestational age in mid-pregnancy - namely, from the date of the last menstrual period; from clinical examination of the size of the uterus; and from an ultrasound examination. The final estimate may be a composite of all these. In addition, gestational age may be assessed shortly after birth by the Dubowitz scoring system. ${ }^{4}$ All these methods inevitably suffer from some degree of observer variation and are subject to normal biological variation. We have carried out an investigation to study the accuracy with which gestational age may be estimated in mid-pregnancy and the possible influence that any imprecision might have on the accuracy of subsequent classification of the patient's AFP concentration as normal or abnormal. We used the Dubowitz assessment as the independent standard against which the other methods were judged.

\section{Patients and methods}

We initially admitted into the study 131 women attending for booking at the professorial antenatal clinics at the University Hospital 